\title{
Use of Small Specimen Creep Data in Component Life Management: A Review
}

\author{
Charles Craddock Dyson*, Wei Sun, Chris J Hyde, Steve J Brett, Thomas H Hyde \\ Department of Mechanical, Materials and Manufacturing Engineering \\ University of Nottingham, Nottingham NG7 2RD UK
}

\begin{abstract}
Small specimen creep testing techniques are novel mechanical test techniques that have been developed over the past 25 years. They mainly include the sub-size uniaxial test, the small punch creep test, the impression creep test, the small ring creep test and the two bar creep test. This paper outlines the current methods in practice for data interpretation as well as the state of the art procedures for conducting the tests. Case studies for the use of impression creep testing and material strength ranking of creep resistant steels is reviewed along with the requirement for the standardization of the impression creep test method. A database of small specimen creep testing is required to prove the validity of the tests.
\end{abstract}

Keywords: Small specimen creep testing; Data interpretation; Power plant components; Life Management

*Corresponding author: Tel:+44 1158467683 email: ezxcd3@nottingham.ac.uk. 


\section{Nomenclature}

a Major axis dimension of small ring creep test

$a_{p} \quad$ Receiving hole radius, small punch test

$B \quad$ Material constant in Norton's law

$B^{\prime} \quad$ Replacement material constant in Norton's law, for small punch conversion

$b \quad$ Minor axis dimension of small ring creep test

$b_{i} \quad$ Length of impression specimen

$b_{t} \quad$ Bar width, two bar specimen

$C_{L M} \quad$ Constant in the Larson-Miller relationship

$D \quad$ Diameter of small punch specimen

$D_{r} \quad$ Reference multiplier in the reference stress method

$d_{i} \quad$ Width of impression creep indenter

$d_{G L} \quad$ Diameter of gauge of sub-size uniaxial specimen

$G L \quad$ Gauge length of sub-size uniaxial specimen

$h \quad$ Thickness of impression specimen

$K_{s p} \quad$ Small punch correlation factor

$k \quad$ Dimension of two bar specimen

$k_{1} \quad$ Constant in the Wilshire equations

$k_{s} \quad$ Pipe system loading factor

$l \quad$ Full size uniaxial gauge length

$l_{e} \quad$ Small specimen equivalent gauge length

$n \quad$ Norton's law stress exponent

$P \quad$ Applied load

$P_{L M} \quad$ Larson-Miller parameter

$\bar{p} \quad$ Impression creep indenter pressure

$Q^{*}{ }_{c} \quad$ Wilshire equations, apparent activation energy

$R \quad$ Ideal gas constant

$R_{s} \quad$ Radius of small punch ball/hemispherical punch head

$T$ Temperature

$t_{0} \quad$ Initial thickness of small punch specimen

$u \quad$ Constant in Wilshire equations

w Width of impression specimen

$\alpha \quad$ Scaling factor in the reference stress method

$\alpha_{c} \quad$ Multiaxiality constant

$\beta \quad$ Reference stress parameter

$\dot{\Delta} \quad$ Displacement rate

$\dot{\Delta}_{s s} \quad$ Steady-state displacement rate

$\Delta^{c} \quad$ Creep displacement

$\Delta_{i} \quad$ Initial deflection

$\Delta_{t} \quad$ Total deflection

$\dot{\varepsilon}^{c} \quad$ Creep strain rate

$\varepsilon^{c} \quad$ Creep strain

$\dot{\varepsilon}_{0} \quad$ Initial creep strain rate

$\eta \quad$ Reference stress parameter

$\sigma \quad$ Applied stress

$\sigma_{T S} \quad$ Ultimate tensile stress

$\sigma_{\text {nom }} \quad$ Nominal stress

$\sigma_{\text {ref }} \quad$ Reference stress

$\sigma_{A X}^{A} \quad$ Allowable axial stress

$\sigma_{A X}^{C E} \quad$ Closed end axial stress

$\sigma_{A X}^{M A X} \quad$ Maximum axial stress

$\Omega \quad$ Omega method material creep damage susceptibility parameter 


\section{Introduction}

Creep is a time dependant phenomenon that affects materials under stress when operating at high temperatures for extended periods. The situation in many countries is that the coal fired power plants operate well beyond their design lives ( $\sim 25$ years). For example the last dedicated coal fired plant in the UK was built over 40 years ago [1]. In these time frames, creep damage becomes a significant and dominant failure mode for high temperature components. Due to the current economic climate the extension of the life of plants is in demand, especially in a manner that allow the continued operation of a tested component using, non-destructive testing methods. Small specimen testing is a 'non-invasive' test technique that is realised through the testing of material taken from small, button-shaped scoop samples obtained from in-service components. The tests are still in the process of development and refinement but have attracted attention do their abilities to produce minimum creep strain rate and creep rupture data from small amounts of material compared to full size uniaxial tests. The associated test techniques and the data interpretation methods however rely on comparisons with uniaxial test data for validation. Current tests still depend on some form of uniaxial data tested on a material or component of choice, although in some cases once the data is obtained the small specimen creep tests can then operate independently using the uniaxial data as a reference point. In addition due to the small amounts of material obtained, small specimens have the potential to be used in novel alloy development [2,3].

The ability to extract mechanical data from a non-destructive test is unmatched by any other life management method, hence the requirement for small specimen methods. This paper reviews the methods currently employed for the use of small specimen testing in life management, prediction and remaining life assessment. Power plant steels mentioned in this paper are detailed in Table 1.

\section{Non-stand Small Specimen Creep Testing}

Small specimen creep testing methods have gained a lot of interest in recent years due to the need to use small samples of simple geometry to produce rupture data and aid in the remnant life assessment of high temperature components. They mainly consist of the conventional sub-size uniaxial creep test, the impression creep test, the small punch creep test, the small ring test and the two bar test, all shown in Fig.1. 
Table 1: Standard power plant steels (BS EN 10216-2) by composition (mass \%) and creep rupture strength. [79]

\begin{tabular}{|c|c|c|c|c|c|c|c|c|c|c|c|c|c|c|c|}
\hline \multicolumn{2}{|c|}{ Steel name } & \multirow{2}{*}{ C } & \multirow{2}{*}{$\mathbf{S i}$} & \multirow{2}{*}{ Mn } & \multirow{2}{*}{$\mathbf{P}$} & \multirow{2}{*}{$\mathbf{S}$} & \multirow{2}{*}{$\mathrm{Cr}$} & \multirow{2}{*}{ Mo } & \multirow{2}{*}{$\mathbf{N i}$} & \multirow{2}{*}{$\mathbf{A l}_{\text {tot }}$} & \multirow{2}{*}{$\mathrm{Cu}$} & \multirow{2}{*}{$\mathrm{Nb}$} & \multirow{2}{*}{$\mathrm{Ti}$} & \multirow{2}{*}{$\mathbf{v}$} & \multirow{2}{*}{$\begin{array}{c}100000 h \\
\text { Creep } \\
\text { rupture } \\
\text { strength } \\
6^{600^{\circ} \mathrm{C}} \\
(\mathrm{MPa})\end{array}$} \\
\hline Standard & Colloquial & & & & & & & & & & & & & & \\
\hline 14 MoV6-3 & $0.5 \mathrm{CrMoV}$ & $0.10-0.15$ & $\begin{array}{l}0.15- \\
0.35\end{array}$ & $\begin{array}{l}0.40- \\
0.70\end{array}$ & 0.025 & 0.010 & $\begin{array}{l}0.30- \\
0.60\end{array}$ & $\begin{array}{l}0.50- \\
0.70\end{array}$ & $\leq 0.30$ & $\leq 0.04$ & $\leq 0.30$ & $\cdots$ & $\cdots$ & $\begin{array}{l}0.22- \\
0.28\end{array}$ & 41 \\
\hline 10CrMo9-10 & P22(2.25CrMo) & $0.08-0.14$ & $\leq 0.5$ & $0.3-0.7$ & 0.02 & 0.01 & $\begin{array}{l}2.00- \\
2.50\end{array}$ & $\begin{array}{c}0.90- \\
1.10\end{array}$ & $\leq 0.30$ & $\leq 0.04$ & $\ldots$ & $\cdots$ & $\cdots$ & $\ldots$ & 35 \\
\hline $\begin{array}{c}\text { X10CrMoVNb9- } \\
1\end{array}$ & P91 & $0.08-0.12$ & $\begin{array}{c}0.20- \\
0.50\end{array}$ & $\begin{array}{c}0.30- \\
0.60\end{array}$ & 0.02 & 0.005 & $8.0-9.5$ & $\begin{array}{l}0.85- \\
1.05\end{array}$ & $\leq 0.40$ & $\leq 0.02$ & $\leq 0.30$ & $\begin{array}{c}0.06- \\
0.10\end{array}$ & $\leq 0.01$ & $\begin{array}{c}0.06- \\
0.1\end{array}$ & 90 \\
\hline
\end{tabular}




\subsection{Currently Used Small Specimen Creep Test Methods}

\subsubsection{Conventional Sub-size Creep Test}

The conventional sub-size creep test is essentially a miniaturised conventional 'uniaxial' creep test specimen. The size of the specimen is limited, due to the size of the scoop samples which are removed via non-invasive scoop sampling of power plant components comprising low alloy steels e.g. $0.5 \mathrm{CrMoV}, 2.25 \mathrm{CrMo}$. Scoop samples are typically oval hemispheres with dimensions 30x20x3mm. Depending on the mean grain size of the test material the diameter of the gauge region of the test specimen may vary between 1-3mm in diameter and 5-12mm gauge length [5]. A typical full size uniaxial specimen may have a $5-10 \mathrm{~mm}$ gauge diameter and $30-50 \mathrm{~mm}$ gauge length [6]. Once the preliminary cylinder is machined out (Fig.1a), in order for loading to be applied to the specimen, grips must be electron or laser beam welded to the top and bottom surfaces of the cylinder $[7,8]$. These welding methods are used in order to reduce the size of the heat-affected zone. The dimensions of the specimen warrant this in order for creep mechanisms to occur primarily in the base material, effectively minimising the effects of welds. Due to the elevated temperatures and stresses during testing, samples may require the use of an inert atmosphere within the test furnace, because oxidation effects are substantial on small specimens. Comparing the data with that in air it has shown that in an argon-rich environment the creep curves compare more favourably with those of conventional full size uniaxial specimens [9].

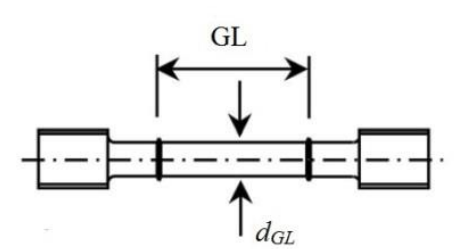

(a)

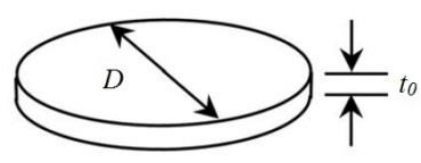

(b)

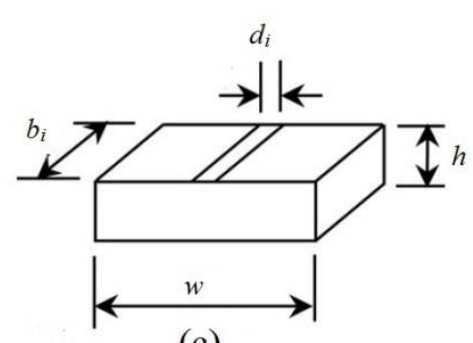

(c)

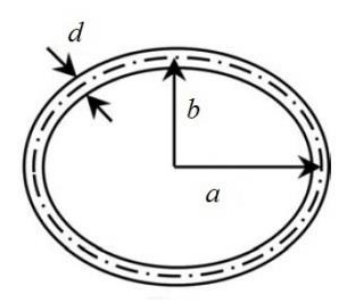

(d)

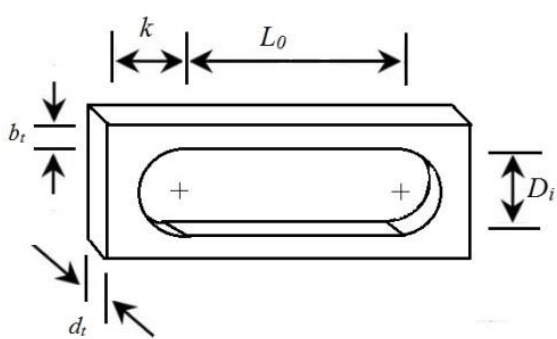

(e)

Figure 1: Shapes and dimensions of small creep test specimens: (a) conventional sub-size uniaxial specimen (GL $\approx 5-$ $12 \mathrm{~mm}$; $\left.d_{G L} \approx 1-3 \mathrm{~mm}\right)$; (b) Small punch creep test specimen $\left(D \approx 8 \mathrm{~mm}\right.$; $\left.t_{0} \approx 0.5 \mathrm{~mm}\right)$; (c) Impression creep test specimen ( $w \approx 10 \mathrm{~mm} ; b_{i} \approx 10 \mathrm{~mm} ; d_{i} \approx 1 \mathrm{~mm}$, and depth $b_{o} \approx 2 \mathrm{~mm}$ ); (d) elliptical small ring creep test $(a \approx 15 \mathrm{~mm}, b \approx 7.5 \mathrm{~mm}, d \approx$ $1 \mathrm{~mm} ; h \approx 2.5 \mathrm{~mm}$ ); (e) two bar specimen ( $L_{0} \approx 13 \mathrm{~mm}, b_{t} \approx 2 \mathrm{~mm}, D_{i} \approx 5 \mathrm{~mm}$ and $k \approx 6.5 \mathrm{~mm}$ ) adapted from [4]. 


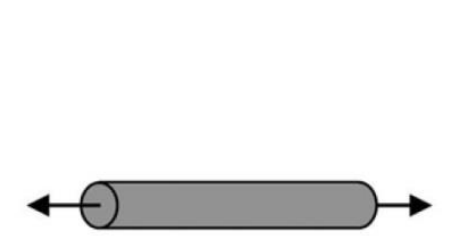

(a)Sub-size uniaxial

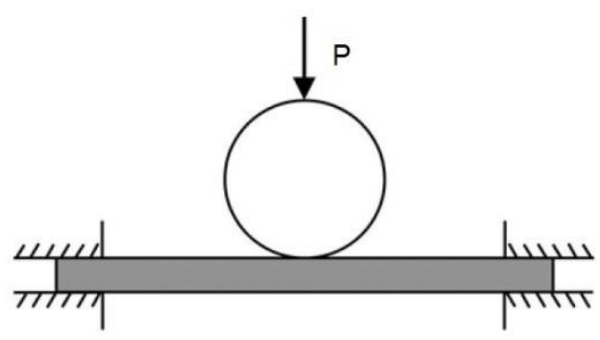

(b)Small punch creep test

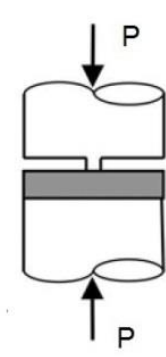

(c)Impression creep test

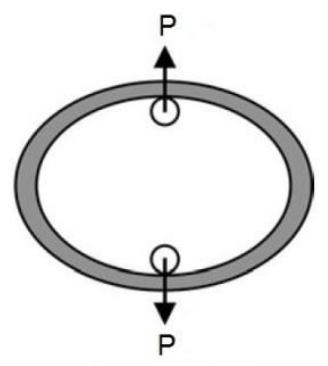

(d)Small ring creep test

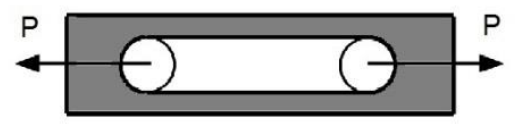

(e) Two bar creep test

Figure 2: Schematics of small specimen loading modes, adapted from [4]

These miniature specimens are also able to produce the full creep strain curve including time to rupture and data conversion is simple as geometries and loading are the same, but considering the complexity of the manufacturing process can be costly to manufacture in comparison to other small test specimens. Handling of the specimen may prove difficult as well, as loading is limited due to the gauge diameter, a higher emphasis is on temperature control. In addition alignment of the loading arrangement is known to be a problem and may cause unwanted bending stresses [7].

\subsubsection{Impression Creep Test Method}

The impression creep test, a $10 \times 10 \times 2.5 \mathrm{~mm}$ specimen loaded by a rectangular indenter of width $d_{i}=1 \mathrm{~mm}$ but if material is scarce an $8 \times 8 \times 2 \mathrm{~mm}$ specimen can be used that is loaded by a $d_{i}=0.8 \mathrm{~mm}$ wide indenter. The indenter and specimen are defined by three ratios, $w / d i, w / b i$ and $h / d i$ as seen in Fig.1c which allows for the scaling down of the specimen size. The test is compressive in nature and is only able to produce primary and secondary stages of the traditional creep curve reliably, so crucially, it is not able to produce rupture data directly. Where the impression strain rate can be shown to be the same as the uniaxial minimum creep strain rate obtained under equivalent test conditions, rupture times can be extrapolated to indirectly, using the Monkman-Grant correlation and uniaxial rupture times, expanded on later, sect 3.2.1. Due to the simplicity of the specimen geometry, preparation is relatively easy, although careful consideration must be made in grinding the contact surfaces of the specimen so as to remove any machining marks and reduce any residual stresses [10]. Furthermore the indenter must be made of a material of significantly higher creep strength than the test material, so that creep occurs predominantly in the specimen. The aim is to maximise contact with the indenter of the specimen so it would be beneficial to have an indenter that extends across the full width of the specimen. Since the test has been used extensively to test low alloy ferritic $0.5 \mathrm{CrMoV}$ and high chromium martensitic P91 
pipework, nickel based superalloy indenters have commonly been used to load the specimen [11] although it has been shown a ceramic loading jig can also be used [12]. Tests are usually performed at constant load and constant temperature. Important data obtainable from the test are the mean indenter pressure $\bar{p}$ which can be can be converted to the corresponding uniaxial stress $\sigma$ by the reference stress approach [13]

$$
\sigma=\eta \bar{p}
$$

and the creep displacement $\Delta^{\mathrm{c}}$ which can be converted to the uniaxial creep strain $\varepsilon^{\mathrm{c}}$

$$
\varepsilon^{c}=\frac{\Delta^{c}}{\beta d_{i}}
$$

where $\eta$ and $\beta$ are conversion constants or "reference parameters" and $d_{i}$ is the indenter width. $B d_{i}$ is the equivalent gauge length fo the specimen, which will be expanded on later, and is the relation used to the relate the geometry of the impression creep test specimen to that of a uniaxial specimen, The conversion factors allow for the comparison of the minimum creep strain rate in Fig. 3a. Although the test does not produce rupture data is has other benefits in that once a steady state displacement rate is reached, the load or temperature levels can be altered on a single specimen to produce multiple sets of minimum creep strain rate data from the same test specimen [11] (Fig. 3b). The indentation depth into the specimen should be shallow compared to the specimen thickness and indenter width (hence the name impression) and the contact area must be large enough so that the region undergoing creep consists of enough grains so as to ensure that bulk properties can be obtained.

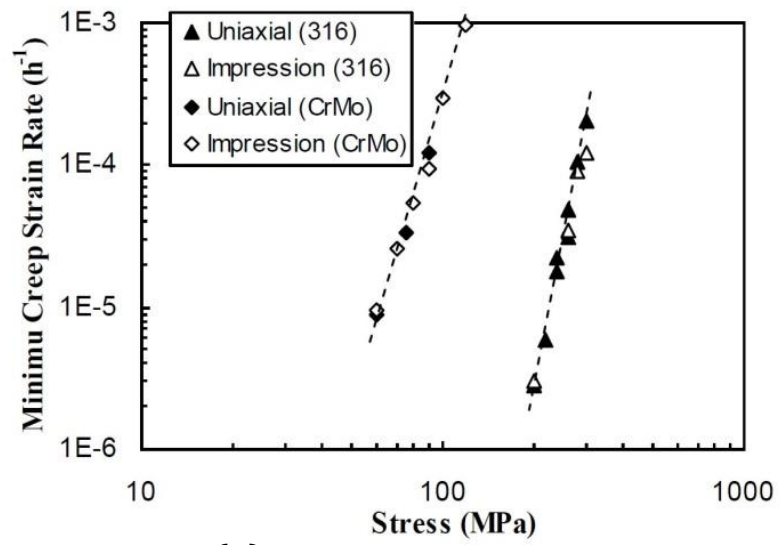

(a)

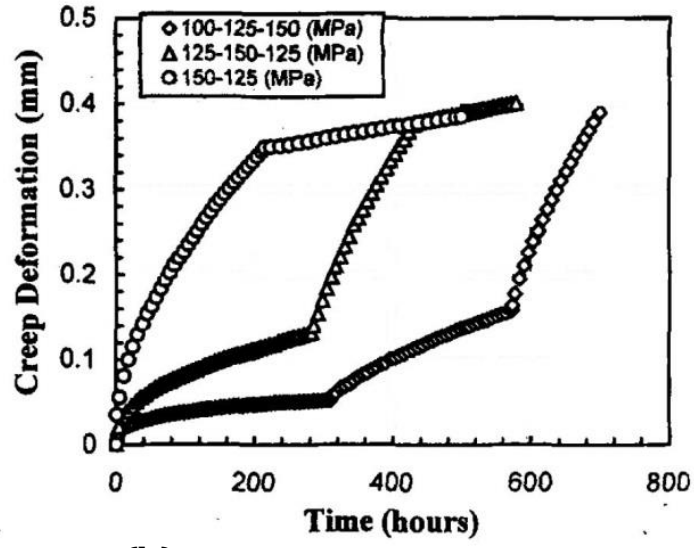

(b)

Figure 3: (a) Comparison of impression creep strain rate data to that of uniaxial data for 316 stainless steel at $600^{\circ} \mathrm{C}$ and $2.25 \mathrm{CrMo}$ weld metal at $640^{\circ} \mathrm{C}$ [15] (b) Creep deformation of impression creep tests for the $0.5 \mathrm{Cr} 0.5 \mathrm{Mo} 0.25 \mathrm{~V}$ steel at $565^{\circ} \mathrm{C}[14]$. 


\subsubsection{Small Punch Creep Test}

Similar to the impression creep test, small punch creep test samples are of a simple geometry and are relatively easy to manufacture out of samples scooped from in-service components. Specimens are generally machined and mechanically polished, sometimes with diamond [16], to achieve a surface finish. The test specimen is a disc of diameter D $=8-10 \mathrm{~mm}$ and thickness $t_{0} \approx 0.2-0.5 \mathrm{~mm}$ and is centrally loaded by a hemispherical punch head or ceramic ball of diameter $2-2.5 \mathrm{~mm}$ [17]. The specimen may be clamped by upper and lower dies, the punch is pushed through the lower die which usually has a receiving hole radius of $\approx 2 \mathrm{~mm}$. The test can be performed in two separate ways, constant deflection rate or constant load [18]. The latter is more analogous to a full size uniaxial creep test and although a 'standard' data interpretation and correlation method does not exist, in Europe the CEN workshop agreement [19] provides a relationship between the punching force and the membrane stress for an established geometry (initial thickness $=0.5 \mathrm{~mm}$, punch radius $=1.25 \mathrm{~mm}$, receiving hole radius $=2 \mathrm{~mm}$ ), based on Charkrabarty's theory for stretch forming over a hemispherical punch head [20]

$$
\frac{P}{\sigma}=3.33 K_{s p} a_{p}^{-0.2} R_{s}^{1.2} t_{0}
$$

where $a_{p}$ is the radius of the receiving hole, $\mathrm{R}_{\mathrm{s}}$ is the radius of the punch indenter and $\mathrm{t}_{0}$ is the initial specimen thickness. $K_{s p}$ is an empirically determined material dependant correlation factor which allows the fitting of the small punch rupture data to that of uniaxial rupture data. The correlation factor is set to 1 during initial testing and by performing a recommended minimum of 5 tests at a single temperature; the correlation factor can be corrected to the actual value that allows for the alignment with uniaxial data tested on the same sample of material. What this correlation fails to incorporate is the large initial plastic deformation [21] involved upon first contact, which has an effect on the creep properties of the material. Consequently this section is disregarded from the considered deflection $\left(\Delta^{\mathrm{c}}=\Delta_{\mathrm{t}}-\Delta_{\mathrm{i}}\right)$, otherwise a curve is produced which resembles the three stages of a conventional creep curve (Fig.4a) although it is debatable as to whether the curve represents pure creep behaviour [17]. Furthermore the progression of the test consists of the interaction of several non-linearities, which include large initial (local) plastic strains, nonlinear material behaviour, non-linear contact interactions e.g between the specimen and punch, and complex multi-axial stress/strain/damage states in the specimen which evolve in time [22]. This culminates in the differential expansion of the test-piece during loading which means that there is no unified behaviour within the material during deformation i.e. contact regions are changing with time during the test [23]. Also, depending on load levels, the specimen will tend to fracture in two separate modes, one which is around the contact edge (crown) of the punch head [24], and the other being the side wall. Otherwise rupture data tend to agree well with uniaxial rupture data (Fig.4b). 


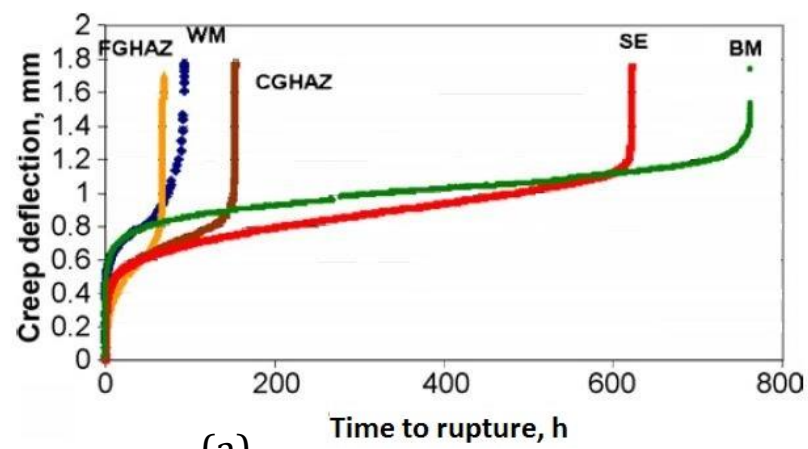

(a)

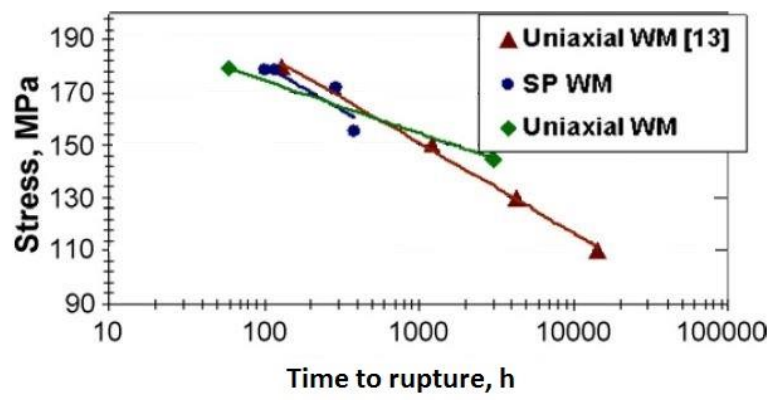

(b)

Figure 4: (a) Typical small punch curves from the fine grained heat affected zone (FGHAZ), the weld material (WM), the coarse grained heat affected zone (CGHAZ), service exposed material (SE) and the base/parent material (BM) of a $9 \mathrm{Cr} 1 \mathrm{Mo} 1 \mathrm{~V}$ weldment under the same test conditions, $250 \mathrm{~N}, 600^{\circ} \mathrm{C}(\mathrm{b})$ Uniaxial and small punch weld metal rupture times $600^{\circ} \mathrm{C}[25]$.

\subsubsection{Small Ring Creep Test}

The small ring creep test is a recently proposed sensitive small specimen creep test that through the use of elliptical geometry is able to produce accurate creep strain-rate data as deformations during testing are large. The merit is that the loads required are low in comparison to the impression creep test due to the relatively small strains. This is as a result of the low equivalent stress required due to the geometry [26] (Fig.1d) which has a large equivalent gauge length when converting data to reference uniaxial data. The specimen is diametrically loaded (Fig.2d) while measuring the load-line deformation of the specimen. Due to the loading and deformation modes, the loading pins required do not need to be of much greater creep strength than the tested material, so strong alloys such as those that are nickel based can be tested [27]. Hyde and Sun [28] developed analytical conversion parameters to relate the applied load $P$ and load line deformation rate $(\dot{\Delta})$ to the uniaxial reference stress and creep strain rate $\left(\dot{\varepsilon}^{c}\right)$, respectively, for which detailed derivations can be found in [28]

$$
\begin{gathered}
\sigma_{\text {ref }}=\eta \frac{P a}{b_{0} d^{2}} \\
\dot{\varepsilon}^{c}\left(\sigma_{\text {ref }}\right)=\eta \frac{d}{4 a b \beta} \dot{\Delta}
\end{gathered}
$$


where $\eta$ and $\beta$ are reference parameters attained in a similar way to the impression creep test method and expanded on in sect 2.2.1. $a$ and $b$ are the major and minor axis dimensions of the elliptical specimen, $b_{0}$ is the specimen depth and $d$ and is the thickness of the specimen (Fig. 1d).

\subsubsection{Small Two-Bar Creep Test}

The latest of all the small specimen creep tests in development is the two-bar specimen. The test [29] is used to obtain rupture data from small samples with the interpretation complications that arise with the small punch creep test. The specimen is a thin rectangular bar that has had its centre machined out (Fig. 1e) with semi-circular provisions into which the loading pins sit which provide a tensile axial force to the parallel bars. The load-line deformation and applied load can then be converted into corresponding uniaxial creep strain-rates and stresses. The specimen dimension ratios, $L_{0} / D_{i}, k / D_{i}$ and $b_{t} / D_{i}$ (Table 2 ) are designed so that $\eta$ and $\beta$ are close to unity $(0.997$ and 1.456 respectively), with recommended ratios of $2.6,1.13$ and 0.4 respectively:

Table 2: Recommended dimension ratios for the small two-bar specimen [29]

\begin{tabular}{lr}
\hline Dimension ratios & Range \\
\hline$L_{0} / D_{i}$ & $\sim \geq 2.0-5.0$ \\
$k / D_{i}$ & $\sim \geq 1.0$ \\
$b_{t} / D_{i}$ & $\sim \geq 0.2-0.47$ \\
\hline
\end{tabular}

Two bar specimen constructed of P91 steel at $600^{\circ} \mathrm{C}[30]$ produced comparable results to full size uniaxial tests once conversions have been made. Non-simultaneous failure of the two bars, can cause bending in the intact bar [30], however, this occurs close to the termination of the test.

\subsection{Data Conversion}

The non-standard small specimens have unconventional geometries, which if tested in isolation would produce unfamiliar data that would have difficult to apply to engineering components. The methods below convert the data into familiar results that are comparable with full size uniaxial creep tests (Figs 3a, 8a, 11b).

\subsubsection{The Reference Stress Method}

The reference stress approach to data interpretation has been found to be a versatile technique that allows the interpretation of data from the latter four of the non-standard small specimen creep test techniques $[28,29,31,32]$.

Mackenzie [33], assumes that a material obeys Norton's law, $\dot{\varepsilon}^{c}=B \sigma^{n}$, where $B$ and $n$ are material constants, for a full size uniaxial creep tests assumed to creep at the same rate, there is a value of $\sigma$ that for all values of $n$ satisfies the Norton's law relationship above, this is called the reference stress. Then through the use of reference multipliers 
in conjunction with the reference creep strain rate, a relationship can be formed with the steady state displacement rate:

$$
\dot{\Delta}_{s s}=D_{r} \dot{\varepsilon}^{c}\left(\sigma_{r e f}\right)
$$

$\dot{\Delta}_{\mathrm{ss}}$ is the material steady state displacement rate, $D_{r}$ is the reference multiplier mentioned above $\left(D_{r}=\beta d\right)$, where $\beta$ is an empirically measured constant which is multiplied by the characteristic dimension $d$ of the test specimen. $D_{r}$ is made to be independent of $n$ by introducing a scaling factor $\alpha$ into the function of the deformation rate of the creeping structure, where dim represents dimension quantities that pertain to the analytical solution of the structure.

$$
\dot{\Delta}_{s s}=\frac{f_{1}(n)}{\alpha^{n}} f_{2}(\operatorname{dim}) B\left(\alpha \sigma_{n o m}\right)^{n}
$$

The reference stress is $\sigma_{\text {ref }}=\alpha \sigma_{\text {nom }}$ and $\eta$ is the value of $\alpha$ that causes $D$ to be independent of the stress exponent.

$$
D_{r}=\frac{f_{1}(n)}{\eta^{n}} f_{2}(\text { dim })=\text { Constant }
$$

The reference stress in simple structures (i.e. beams or thick cylinders) corresponds to the skeletal point of the structure, which is the intersection of stress distributions through the structure that arise from different stress exponents $n$ under creep conditions [13]. For more complex structures, numerical methods [34, 35] are used to obtain $\eta$ for cases where a computed creep solution has been found, by using several values of $n$ and plotting them against $\log \left[\dot{\Delta}_{\text {ss }} /\left(B\left(\alpha \sigma_{\text {nom }}\right)^{n}\right]\right.$ for guessed $\alpha$ values, where $\eta$ is the value of $\alpha$ that causes $\dot{\Delta}_{\text {ss }} /\left(B\left(\alpha \sigma_{\text {nom }}\right)^{n}\right.$ to be constant (Fig. 5).

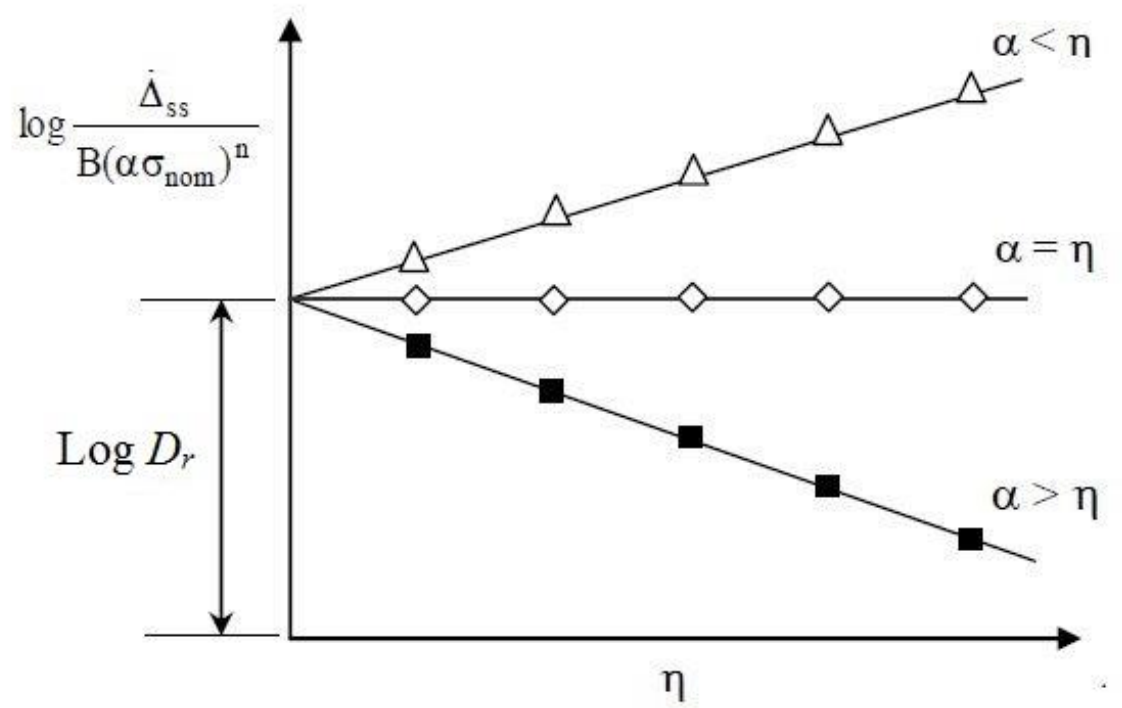

Figure 5: Schematic diagram illustrating the use of FE analysis to obtain reference parameters [15].

The method is geometry dependant, therefore in its current from can only be applied to the impression creep test, small ring creep test and two bar creep test. As the geometry 
of the small punch creep test changes during loading, Hyde et al. [32] proposed a method for correlating the minimum displacement rate to the uniaxial creep strain rate by replacing $B$ in the Norton creep law $\left(\dot{\varepsilon}=B \sigma^{n}\right)$ with $B^{\prime}=(1+\varepsilon)^{n} B$.

\subsubsection{Equivalent Gauge Length}

This is a tool that is used to relate the different geometries of all the individual nonstandard small specimen tests to that of the full size uniaxial test specimen. The gauge length ' $l$ ' used in conventional uniaxial creep tests and the sub-size uniaxial creep test constitutes the creep deformation as a fraction of the working gauge length, eq. 9 . The equivalent gauge length ' $l_{e}$ 'is a quantity that is derived from the geometry of the specimen in order to create an expression that models the creep strain in the unconventionally shaped small specimen tests to the conventionally shaped specimen

$$
\varepsilon^{c}=\frac{\Delta^{c}}{l}
$$

where $\Delta^{c}$ is the elongation of the test specimen minus any elastic deformation, $l$ the gauge length and $\varepsilon^{c}$ the creep strain. A similar expression exists for small specimen geometries using the equivalent gauge length ' $\mathrm{e}^{\text {' }}$

$$
\varepsilon^{c}=\frac{\Delta^{c}}{l_{e}}
$$

The equivalent gauge length, if related to a reference creep strain becomes $D_{r}=\beta d$. Common conversion geometries along with earlier mention conversion constants have been tabulated by Hyde et al. [28] which gives a representation of how the equivalent gauge lengths are related to the analytical solutions used in the reference stress method (Table 3).

Table 3: Summary of correlation formulae $[28,29]$

\begin{tabular}{ccccc}
\hline Specimen & $\boldsymbol{\sigma}_{\text {nom }}$ & $\boldsymbol{\eta}$ & $\boldsymbol{\beta}$ & $\boldsymbol{\beta d}\left(\mathbf{l}_{\mathrm{e}}\right)$ \\
\hline Sub-size uniaxial & $\frac{4 P}{\pi d_{G L}^{2}}$ & 1 & 1 & 1 \\
Impression & $\frac{P}{b_{i} d_{i}}$ & $\sim 0.4$ & $\sim 2.0$ & $\sim 2 d_{i}$ \\
$\begin{array}{c}\text { Small ring } \\
\text { (elliptical) }\end{array}$ & $\frac{P a}{b_{0} d^{2}}$ & 0.892 & $\sim 0.3-0.7$ & $\frac{4 a b \beta}{d}$ \\
$\begin{array}{l}\text { Small ring } \\
\text { (circular) }\end{array}$ & $\frac{P}{2 b d}$ & 0.892 & 0.448 & $\frac{4 R^{2} \beta}{d}$ \\
Two bar & $\frac{P}{2 b_{t} d_{t}}$ & $\sim 1$ & $\sim 1.4$ & $\beta L_{0}$ \\
Small punch & $\frac{P}{2 \pi R_{s} t_{0}}$ & $K_{s p}\left(a_{p} / R_{s}\right)$ & & $\ldots$ \\
\end{tabular}

*Large deformation effects, complex geometry and deformation behaviour of the small punch creep test make it difficult to define material and deformation independent parameters. 


\section{Current Practice Using Small Specimen Data for Power Plant Components}

\subsection{General Procedure}

\subsubsection{Identification of the Components}

Components at risk of creep failure are those that undergo the most severe temperature, pressure conditions and service history, and usually are the life-limiting components of a power plant. These include superheater headers, reheater headers, main steam and reheat pipe lines, turbine casings, steam chests and valve bodies [37]. Pressures in the piping components can be above 200 bar and temperatures above $500^{\circ} \mathrm{C}$ [36], modern ultra-supercritical units have temperatures in excess of $600^{\circ} \mathrm{C}$ [36]. With regards to piping and headers the early failures usually occur in the weldments and can be identified due to prior experience (service history), from stress analysis that reveal which areas undergo the highest system loadings and where stress concentrations are likely to occur or from visual inspection [37]. Once plants have reached a significant age there is a shift in focus from the weldment sections to parent material components [38]. The high temperatures and stresses that piping components are exposed to mean that the sections are at risk of axial creep rupture as a result of hoop stress in the parent material section.

$500 \mathrm{MW}$ power plants (or larger) are vast structures for which individual comprehensive assessment of every component is unfeasible. Small specimen creep testing has the potential to slot into a power plant condition assessment strategy, like for example the three stage approach developed by the Electric Power Research Institute, 'EPRI' [36, 39]. The discovery of suspect components during assessment may be tested further to assess creep strength by checking whether the material falls into a creep strength scatter band. If at risk further non-destructive testing can be performed.

\subsubsection{Scoop Sampling}

Small amounts of material may have to be removed for testing [40]. Sample removal should not compromise the structural integrity of the pipe, header or other component being sampled. However removed material must also have sufficient size to enable representative bulk material properties. Scoop sampling has been used on several occasions [11] on both low alloy $0.5 \mathrm{CrMoV}$ ferritic steels and on the newer martensitic steels such as P91 in order to perform impression creep tests. Brett [11] has used the what is called the 'SSam-2' sampler (produced by Rolls Royce) and found that for a wall thickness of $60-65 \mathrm{~mm}$ in main steam pipes and $30-35 \mathrm{~mm}$ in hot reheat pipes

$(0.5 \mathrm{CrMoV})$ the maximum cutting depth could exceed $10 \%$ of the wall thickness that has been shown by Dedov et al. [41] to be within an allowable dimple depth as the resultant stress concentrations are permissible.

The 'SSam-2' [42] sampler (Fig.6) comprises a hollow hemispherical cutter of diameter $50 \mathrm{~mm}$ with an abrasive coating that is connected to a flexible drive shaft. The cutter rotates rapidly while feeding into the surface of the material with the aid of a lever arm taking up to an hour to remove a well-polished 20-40 mm diameter, and 3-4mm thick scoop samples, leaving a high surface finish on the pipe excavation site. In principle 
smaller samples have the potential to be removed from pipes with thinner wall sections, but this has yet to be put into practice.

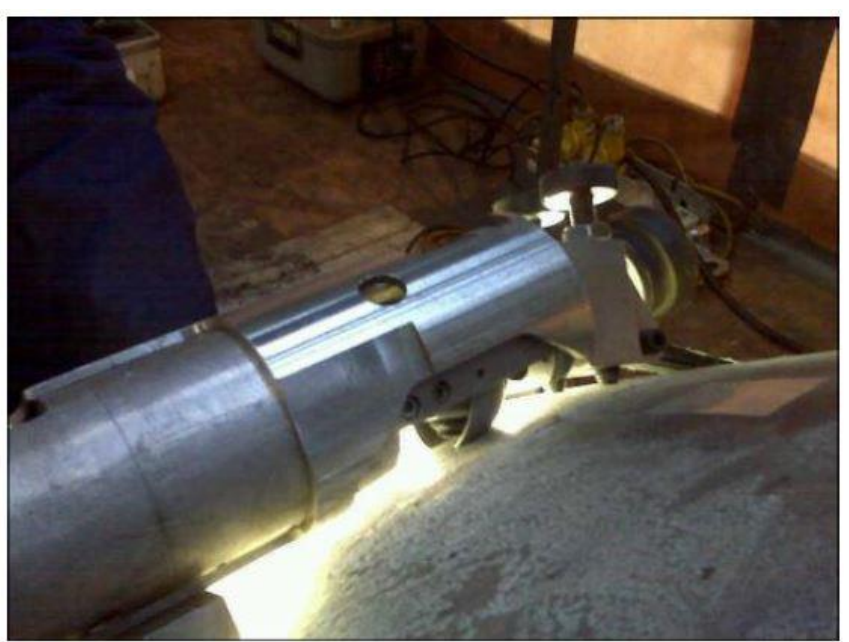

Figure 6: Scoop sampling in progress [43]

EPRI [44] have documented alternative samplers such as the Low Cost Scoop Sampler also developed by Rolls Royce. Dedov et al. [41] have used the Mechanical Sampling Machine, referred to as the 'MSM-2' which operates in a similar fashion to Rolls Royce's 'SSam-2', but has a larger cutting diameter of $60 \mathrm{~mm}$.

Rouse et al. [45] conducted a detailed study into the stress fields created upon removal of scoop samples from power plant straight piping under steady state creep conditions. The effect of scoop sampling on three different loading conditions were tested on $0.5 \mathrm{CrMoV}$ piping of external diameter of $360 \mathrm{~mm}$ and wall thickness $60 \mathrm{~mm}$, triaxial material constant $\alpha_{c}=0.3$. Internal pressure loading (closed-end condition), internal pressure loading and additional axial system loading, and internal pressure loading with bending system loading were the cases. A loading factor $k_{s}$, was used to quantify the amount of additional system loading, with 0 being none and 1 total axial stress (closedend condition and system loading) according to the maximum allowable axial load

$$
k_{s}=\frac{\sigma_{A X}^{A}}{\sigma_{A X}^{M A X}-\sigma_{A X}^{C E}}
$$

where $\sigma_{A X}^{A}$ is the additional axial load, $\sigma_{A X}^{M A X}$ is the maximum allowable axial load (limited by $\sigma_{M D H}$, mean diameter hoop stress) and $\sigma_{A X}^{C E}$ is the axial load as a result of the closed end condition. The removal of scoop samples resulted in stress concentrations located at the tip of the notch which increased substantially when the effects of system loading were applied. The effect on the long term creep strength of the pipe section in question was not considered, but this did not cause any long term complications in practice $[11,46,12]$. Furthermore depending on the time of sampling it would be fair to assume that a well formed damage pattern would have accumulated elsewhere in the piping section, and that the introduction of non-invasive dimples would not drastically change those effects. However, further study and/or service experience are required before a safe conclusion can be made. 


\subsubsection{Specimen Type Selection}

Due to the varying advantages and limitations of the non-standard small specimen tests (Table 4) none of them can be used as a global test for all components and material types. This is clear in the inability of some tests to produce rupture data (impression creep test, small ring creep test) but in the cases that don't, minimum creep strain rate data are of a high quality. In addition the production of samples varies significantly as some tests have basic geometries (impression creep test, small punch creep test are essentially plates) whereas others require further processes for sample preparation, the small ring and two bar specimen require electric discharge machining to remove the inner material (Figs.1d,e), and in the case of the sub-size uniaxial test, extra material is required to make the loading grips [7] which are then laser or electron beam welded to the specimen.

The impression creep test has been used extensively in industry to test the minimum creep strain rate data of power plant piping, $0.5 \mathrm{CrMoV}$ steels and newer martensitic P91 steels. Through stepped load/temperature tests is possible to obtain a range of minimum creep strain rates from one sample [47]. Until recently it was unable to test materials of high creep strength, as the indenter use has to be creep strength 2-3 times stronger than the test sample [48]. Ceramic indenters may be used, significantly raising the creep strength of materials that can be tested [12]. This means the test may now be applied to nickel superalloys. However the small ring test also has the capability to obtain an accurate minimum creep strain rate and with its relatively large equivalent gauge lengths is able to produce highly accurate minimum creep strain rate data through loading pins of similar creep strength of the material being tested [27]. It is also possible to test brittle materials [26]. Both of the tests mentioned, however, are unable to produce rupture data directly but could be used indirectly by inputting creep strain rates into the Monkman-Grant correlation to be used with uniaxial rupture data.

The extensively tested small punch test may be used to obtain short term rupture data providing a correlation factor $K_{s p}$ has been previously determined for the material in question, for example values for steel seem to be around 1.2-1.3 [49, 50,4] and that the test conditions including the geometry of the sample, load line of the punch and atmosphere are kept consistent. For the current method of using the $K_{s p}$ the need for a database of commonly used power plant materials at a range of test temperatures could aid the use of such a test for life prediction of components. As mentioned earlier characterization of the full small punch creep test curve is not fully understood which limits the test from obtaining Norton creep law constants $B$ and $n$. The invention of the newer two bar specimen has the potential to produce rupture data as the test sample gauge area deforms parallel to the load line so in theory behaves in a similar fashion to a full-size uniaxial test. Furthermore it has been used successfully in determining constants in the Kachanov-Rabotnov and Liu-Murakami creep damage equations [51]. 


\subsubsection{Creep Testing and Data Processing}

The specimen are manufactured from scooped in-service or ex-service material by electrical discharge machining and in the case of the impression creep test and small punch creep test, a small excess of material is left on the loading surfaces for further grinding and polishing (recommended 200 grit [19]) to achieve a high quality surface finish for the removal of any residual stresses due to machining. The recommended tolerance is set to be $\pm 0.02 \mathrm{~mm}$ for impression creep test [10] and $\pm 0.5 \%$ for small punch test [19]. The small ring and two bar specimens are cut into square and rectangular plates respectively, from which they are wire spark eroded through feed holes at the centre of the plate; the wire electrode is sprayed with coolant so as to produce a better surface finish [30]. All specimens are cut to sample dimensions as shown in Fig.1.

For pneumatic, servo-hydraulic or dead weight, test rigs must be able to hold a constant load controllable to $\pm 1 \%$ as comparable to full size creep rigs (as in BS EN ISO 204:2009 [52]). In the case of the impression creep test, recommended indenters are made of nickel superalloys (WASPALOY or Nimonic) when testing low alloy ferritic or martensitic steels [10] and must be ground so as to be parallel with the flat surface of the specimen. For the small punch test ceramic balls/hemispherical heads should be of sufficient hardness 55HRC so as not to deform under compression. The small ring test requires loading pins of only similar creep resistance, whereas the two bar test has loading fixtures of a much higher stiffness and are generally produced from material with greater creep resistance [29]. The load line displacements are measured using water cooled extensometers and linear variable displacement transducers although strain gauges may be used provided they are accurate to within $\pm 1 \%$ and have sufficient resolution.

Temperature fluctuations should be kept within $\pm 0.25 \%$ [19] or within $\pm 4^{\circ} \mathrm{C}$ for $600<\mathrm{T} \leq 800^{\circ} \mathrm{C}$ [52]. Temperature in most cases is determined with a thermocouple. However, with the small punch test, due to its confined loading environment, poses difficulties. A feed hole may be drilled through the top of the upper die for thermocouple placement [53]. Due to the small sizes of the specimens, oxidation effects can be magnified, reducing overall creep strength [54] of the specimen so the use of an inert atmosphere may be required, usually in the form of metered argon flow. Tested specimens can be seen in Fig.7. For more detail regarding each of the testing procedures refs [10] and [19] provide information pertaining to the impression creep test and small punch test respectively and the ref [30] contains information regarding the small ring test and the two bar test. 


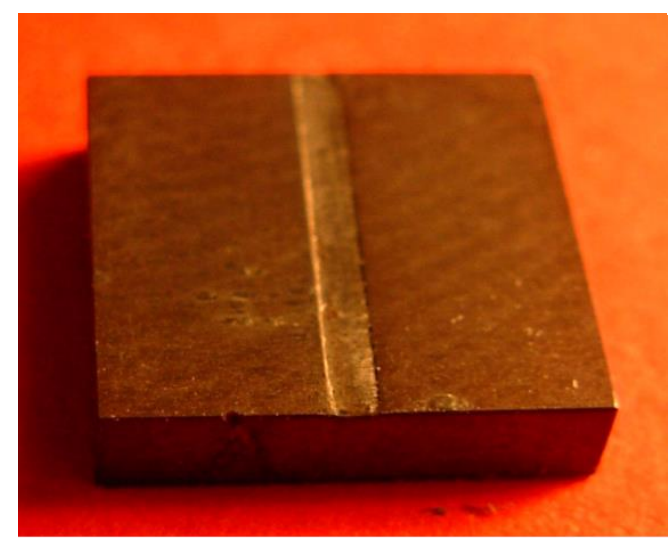

(a)

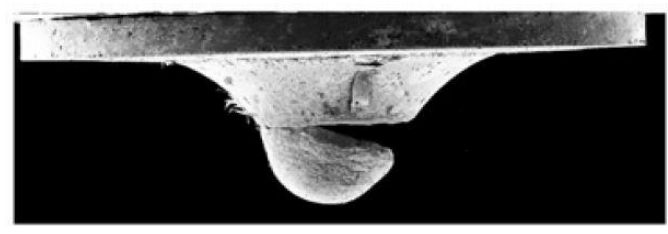

(c)

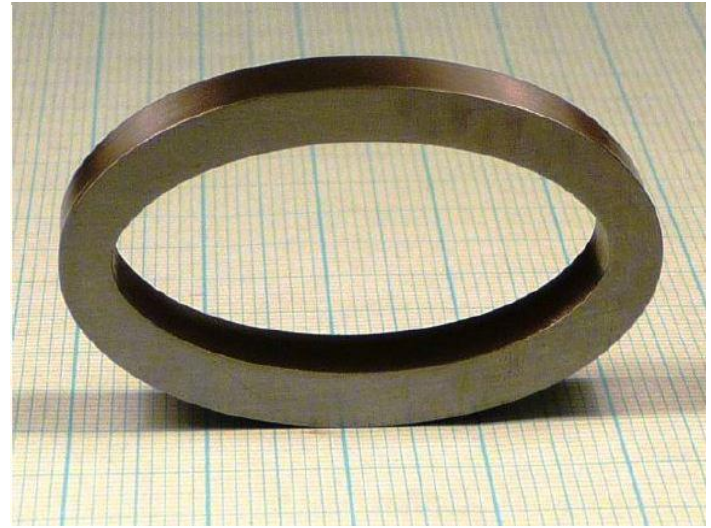

(b)

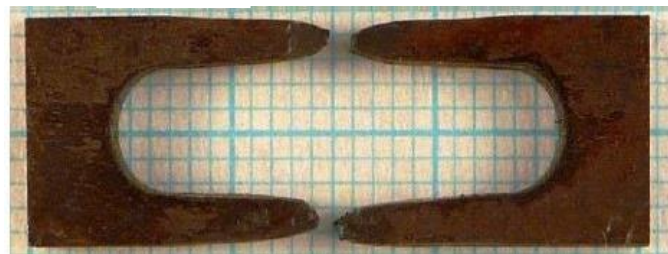

(d)

Figure 7: (a) Tested impression specimen (width $w \approx 10 \mathrm{~mm}$ ), (b) tested elliptical ring specimen (major axis, $a \approx 20 \mathrm{~mm}$ ), (c) ruptured small punch specimen (diameter $D \approx 8 \mathrm{~mm}$ ) and (d) ruptured two bar specimen (length, $L_{0}+2 k \approx 26 \mathrm{~mm}$ ) $[10,25,30]$

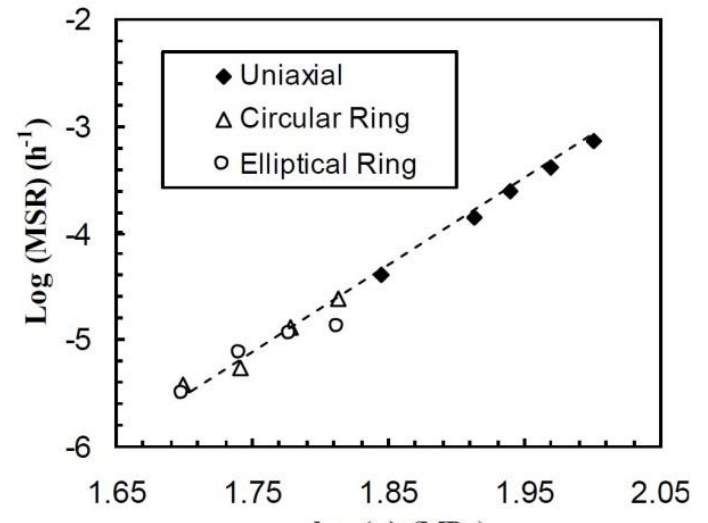

(a)

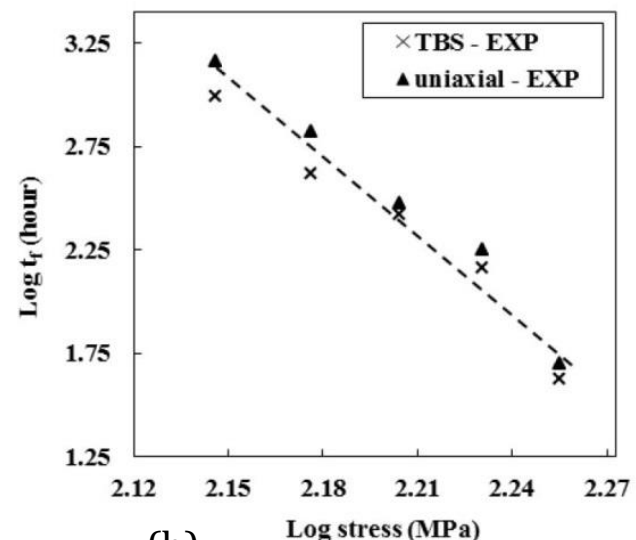

(b)

Figure 8: (a) Minimum creep strain rate data for P91 steel at $650^{\circ} \mathrm{C}$, small ring test and (b) two bar test creep rupture data alongside uniaxial for $\mathrm{P} 91$ steel at $600^{\circ} \mathrm{C}$ [30] 
Table 4: Summary of advantages and disadvantages of small specimen test methods.

\begin{tabular}{|c|c|c|}
\hline Test method & Advantages & Disadvantages \\
\hline Sub-size uniaxial & $\begin{array}{ll}\text { - } & \text { No complex conversion } \\
& \text { required } \\
\text { - } & \text { Uniaxial loading } \\
\text { - } & \text { Produces rupture data }\end{array}$ & $\begin{array}{ll}\text { - } & \text { Relatively complex } \\
\text { manufacturing method } \\
\text { - } & \text { Small gauge diameter } \\
\text { causes difficulties during } \\
\text { loading } \\
\text { - } \quad \text { Sensitive to furnace } \\
\text { atmospheric composition }\end{array}$ \\
\hline $\begin{array}{l}\text { Impression } \\
\text { creep }\end{array}$ & $\begin{array}{ll}\text { - } & \text { Simple geometry } \\
\text { - } & \text { Comprehensive test database } \\
\text { - } & \text { Industrially applied } \\
\text { - } & \text { Effective strength ranking tool }\end{array}$ & 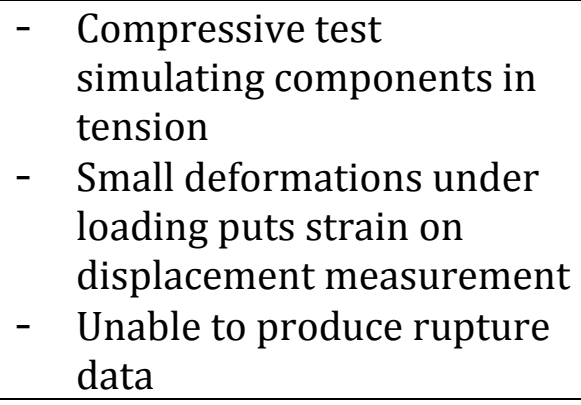 \\
\hline Small punch & $\begin{array}{ll}\text { - } & \text { Simple geometry } \\
& \text { Large amounts of academic } \\
& \text { testing } \\
\text { - } & \text { Draft code of practice exists } \\
\text { - } & \text { Produces rupture data } \\
\text { - } & \text { Short tests useful for } \\
& \text { qualitatively assessing creep } \\
& \text { strength } \\
\end{array}$ & $\begin{array}{ll}\text { - } & \text { Complex Multiaxial stress- } \\
\text { state during loading } \\
\text { - } & \text { Absence of mechanics } \\
\text { based conversion } \\
\text { relationship }\end{array}$ \\
\hline Small ring & $\begin{array}{l}\text { - } \begin{array}{l}\text { Accurate creep strain data as a } \\
\text { result of a large equivalent } \\
\text { gauge length } \\
\text { - } \quad \text { Can test a large range of } \\
\text { materials }\end{array} \\
\end{array}$ & $\begin{array}{ll}\text { - } & \text { Cannot produce rupture } \\
\text { data } \\
\text { - } & \text { Relatively complex } \\
& \text { manufacturing procedure }\end{array}$ \\
\hline Two bar & $\begin{array}{ll}\text { - } & \text { Can produce rupture data } \\
\text { - } & \text { Stable uniaxial loading }\end{array}$ & $\begin{array}{ll} & \text { Material may creep in } \\
\text { regions other than the } \\
\text { gauge region } \\
\text { - } \quad \text { Two bars may creep at } \\
\text { slightly different rates } \\
\text { - } \quad \text { Relatively complex } \\
\text { specimen geometry }\end{array}$ \\
\hline
\end{tabular}

\subsection{Main Applications - How to Use the Small Specimen data}

The exploitation of small scale creep testing falls into two broad categories: component specific assessment, where quantitative creep data are required to support a particular assessment, and surveying to provide creep strength ranking, where a more qualitative, relative value of creep strength may suffice. The two are not entirely separate in that ranking which can accurately place a material within a creep strength scatter band does also provide a quantitative value 


\subsubsection{Component Specific Assessment}

There is a requirement for small specimen data to be used in component specific assessments in lieu of uniaxial data, for example on header sections or steam chests/casings.

In the assessment of internal fatigue cracking on steam chests and valve bodies, it has been argued that the load responsible decays through the wall thickness, thus stifling the growth of the crack before a critical length is reached. The attention is then focused on not letting the rest of the un-cracked component fail by creep with assessment based on small scale testing, thus avoiding the need for weld repair.

Extracting a pure creep curve from the small punch test is still not fully established [17]. So in the absence of an analytical approach, reliable and repeatable empirical correlations between small punch and uniaxial data at equivalent conditions are implemented. The Monkman-Grant equation $\left(\dot{\varepsilon} . t_{f}=C_{M G}\right)$ is a simple correlation in this context, but due to the absence of an identifiable steady-state creep strain rate and the fact that correcting the trend line relies on material ductility (making the test cast specific) significant testing would be required on a specific material to explore these issues. The method is better suited to either the impression creep test or the small ring creep test based on the better quality of the creep strain rate data obtained.

The phenomenological interpretation of the small punch test involves disregarding the primary and secondary regions of the creep curve and focusing only on the rupture time. This is useful if reproducible rupture times and stresses are achieved. The trends observed with small punch rupture data compare favourably with uniaxial tests. Universally agreed correlation factors $K_{s p}$ for a specific material grade and temperature range must be determined. A database can then be established.

Alternatively the two bar test has been shown to produce rupture data that compare favourably with uniaxial data for $\mathrm{P} 91$ at $600^{\circ} \mathrm{C}$. The accelerated test data would need to be extrapolated in order to apply to service conditions. A common extrapolation method is the Larson-Miller parameter (eq. 12) [56] (used with the small punch creep test [57]), well known in the accelerated creep extrapolation of uniaxial tests [58]

$$
P_{L M}=T \cdot\left(C_{L M}+\log t_{f}\right)
$$

where $T$ is the temperature in Kelvin, $t_{f}$ is the rupture life in hours and $C_{L M}$ is a constant originally assigned a value of 20 for all metallic materials, has now been found to vary [58]. It is derived as a result of curve fitting to experimental data and is related to the activation energy for creep fracture.

A relatively new method [59] involves the Wilshire equations, which are based on the assumption that as time to failure (hours) $t_{f} \rightarrow \infty$ the applied stress $\sigma \rightarrow 0$ and $t_{f} \rightarrow 0$ as $\sigma$ $\rightarrow \sigma_{T S}$, the ultimate tensile stress of the material. They have already been applied to fullsize uniaxial creep tests [60]

$$
\sigma / \sigma_{T S}=\exp \left\{-k_{1}\left[t_{f} \cdot \exp \left(Q_{c}^{*} / R T\right]^{u}\right.\right.
$$


where $T, R$ and $Q_{c}^{*}$ are the temperature, universal gas constant and apparent activation energy respectively. Wilshire constants $u$ and $k_{1}$ are then calculated by plotting $t_{f .} \exp \left(-Q_{c}^{*} / \mathrm{RT}\right)$ against $\ln \left[-\ln \left(\sigma / \sigma_{T S}\right)\right.$. The utility of the equations is based on their ability to calculate an apparent activation energy ' $Q_{c}^{* \prime}$ by the superimposition of different temperature data sets from temperature compensated graphs of either rupture time or minimum creep strain rate against normalised stress.

The Omega $(\Omega)$ test method [61] is based on the assumption that once the first stage of creep is over, there is a steady rise in creep strain rate. In the $\Omega$ method, strain is an indicator of damage and is represented by:

taking logarithms gives:

$$
\dot{\varepsilon}^{c}(t) / \dot{\varepsilon}_{0}=\exp \Omega \varepsilon
$$

$$
\log \dot{\varepsilon}^{c}(t)=\log \dot{\varepsilon}_{0}+\Omega \varepsilon
$$

where $\dot{\varepsilon}_{0}$ is the initial strain rate of virgin material and $\dot{\varepsilon}^{c}$ is the strain rate at time $t . \Omega$ is the 'total damage' coefficient, which incorporates creep damage, microstructural changes and the effect of strain rate. It is obtained from the gradient of the line $\mathrm{dln} \dot{\varepsilon} / \mathrm{d} \dot{\varepsilon}$ $=\Omega$, provided a linear relationship exists. Once $\Omega$ is obtained, the remaining life may be estimated through:

$$
t_{f}-t=\frac{1}{\Omega \dot{\varepsilon}(t)}
$$

The extrapolation and remnant life assessment methods mentioned are but special mentions from a host of approaches. More detail on these methods can be found in ref [58] with regards to extrapolation and in ref [78] for an analysis on continuum damage mechanics.

\subsubsection{Material Strength Ranking}

There is a somewhat different requirement for small scale test data in creep strength surveys aimed at identifying the weakest components. The ranking of component creep strength is achieved through the application of the same test to numerous samples. During initial small scale testing on a P91 header [62] enough material was removed to apply multiple small specimen tests (small punch and impression creep), with consistent ranking. Test times were reduced by ranking based on the first part of the punch curve, prior to rupture.

The application of such tests to the US market is to older P22 pipework, as failure is more likely than in newer P91 components [63], where weld failure is the key issue [64]. However the widespread occurrences of aberrant, mis-heat treated (and therefore weaker) P91 does bring these end of life problems to the fore. 


\subsection{Current Practice}

\subsubsection{Impression Creep Test Data}

Minimum creep strain rate data from the impression creep test have been used for strength ranking on in-service piping components and for the characterisation of weldment zones. Most data collected are for $0.5 \mathrm{CrMoV}$ piping for which over 170 tests [11] exist creating an effective database for comparison purposes. The method has been applied to Grade 91 [65] piping with the main concern being aberrant material, inadequately manufactured.

\subsubsection{Small Punch Creep Test Data}

Analysis of rupture life has focused on rupture data from the small punch test to extrapolate back to design temperatures, by using the Larson-Miller parameter, the Dorn equation and the Monkman-Grant correlation or simple a rupture time vs deflection relationship $[66,67,16,68,69]$. The lack of a collated material database seems to be holding back its application to in service applications.

Izaki et al. [57] used a graphical method for converting the punch load. A Larson-Miller plot of punch loads was superimposed over a uniaxial Larson-Miller curve for equivalent test conditions. Punch loads are equivalent to uniaxial stresses if they share the same Larson-Miller parameter. The method was used on $2.25 \mathrm{CrMoV}$, the dominant pipeline material in Japan.

The small punch creep test has been applied to single crystal superalloys for life assessment by Jeffs et al. [59] for the lifing of 'CMSX-4', a second generation single crystal superalloy commonly used alloy in gas turbines [71]. Tested alongside the full size uniaxial test, the load was calculated using the $K_{s p}$ method outlined in the CEN workshop agreement, $Q^{*}$ activation energy was determined for the [001] plane of the crystal and inserted into the Wilshire creep equations (eq. 13) for life prediction. The results compared favourably with those of a full size uniaxial test.

\subsubsection{Use of Other Small Specimen Test Data}

The small ring test has the capability of testing material of high creep strength due to its method of loading (Fig.2d) which allows the loading pins to be made of material of similar creep resistance [27] to the test material. This results in the ability of the test to be run on nickel superalloy turbine blades, such as Inconel 738 [27]. Useful minimum creep strain rate data can be analysed using strain based lifing calculations such as the Monkman-Grant or Omega method. 


\section{Applications in Life Management: Case Studies}

\subsection{Background}

A large proportion of the UKs coal fired plants are well past their design lives [1]. Their high temperature steam lines (main steam, hot reheat and turbine looping) are mainly constructed of $0.5 \mathrm{CrMoV}$ steel and toward the later stages of life there is a shift from weldment failures to parent failures.

P91 steel has been used to replace some $0.5 \mathrm{CrMoV}$ pipework and has also been seen to be used in the newer combine cycle gas turbine stations, but due to inaccurate heat treatment methods, some installed piping samples have unexpected microstructures.

Due to the sheer number $(\simeq 400)$ of steam line items in a typical $500 \mathrm{MW}$ power station [43], comprehensive testing would be uneconomical and time consuming. Impression creep testing is a reliable method for optimising inspection programmes by effectively ranking in-service creep components by creep strength so that effort is focused.

\subsection{Representative examples}

\subsubsection{Creep Strength Ranking for P91}

Grade 91 martensitic steel is a relatively new as a replacement for $0.5 \mathrm{CrMoV}$ steels in the construction of main steam lines. It has better creep strength construction with thinner wall sections [73]. It is, however, more susceptible to manufacturing variations. Aberrant P91 material can be identified using hardness testing and metallographic studies. The hardness should lie in the range of $200-263 \mathrm{HV}$, the aberrant material can be as low as $\sim 151 \mathrm{HV}[74]$.

Once a suspect component has been identified, Brett et al. [46] have shown the capacity for the impression creep test to verify compatibility within the acceptable creep strength scatter band. Fig. 9 shows the stress vs log creep strain relationship for P91 and the mean-20\%, which are converted from stress rupture lines using the modified (Parker) Monkman-Grant relationship (eq. 17) [46] for known uniaxially tested P91 material. Creep strain rates that are found to lie to the right of the mean -20\% line in Fig.9 for a corresponding stress level are said to be acceptable, as they are shown to have a creep strength greater than that of the lower bound.

$$
\dot{\varepsilon}=0.1 t_{f}^{-1.16}
$$

Where $\dot{\varepsilon}$ creep strain per hour and $t_{f}$ is the uniaxial time to failure in hours. 


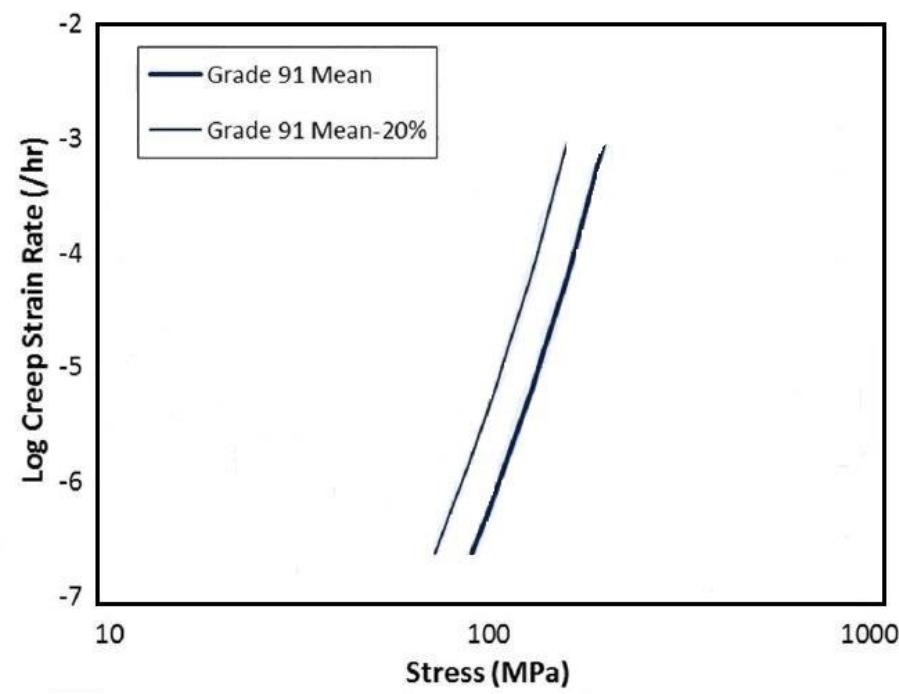

Figure 9: Minimum creep strain rate corresponding to mean and lower bound [75] strength levels at $600^{\circ} \mathrm{C}$

\subsubsection{Vulnerability Assessment of 0.5CrMoV}

$0.5 \mathrm{CrMoV}$ is an established material with regards to impression creep testing. $10 \times 10 \times 2.5 \mathrm{~mm}$ specimens were tested at a proposed standard test regime of $96.7 \mathrm{MPa}$ and $600^{\circ} \mathrm{C}$ [11]. Creep strain rates are compared against a lower bound (mean-20\%); creep strain rates that fall below this, represent materials of potential risk (Fig.10a). The results can then be corrected to find the estimated creep strength at start of life, which may indicate the quality of the initial manufactured product (Fig.10b).

Main steam lines, hot reheat lines, bend and straight pipe sections were tested [11] and compared with data from other power plants. A large database now exists for which creep strain measurements can be compared against.

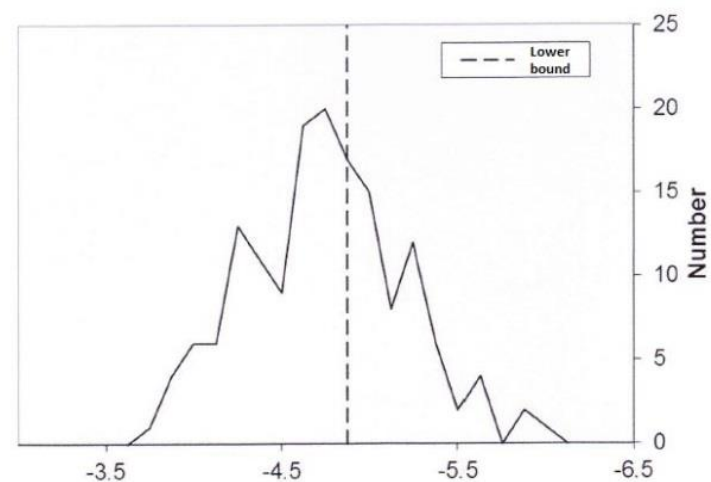

(a)

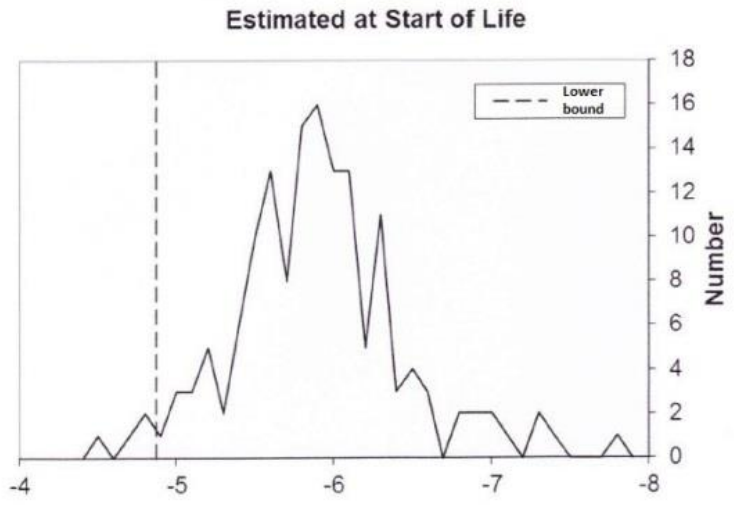

(b)
Lcig Impression Creep Strain Rate (/hr)

Figure 10: Distribution of impression creep strength of specimens (a) as-sampled (b) corrected to start of life [11]. 


\subsubsection{Remaining Life Assessment of Nickel-Based Turbine Blade}

Evaluating turbine blades poses a unique problem as any damage caused to the geometry of the blade renders the blade useless. Furthermore the data obtained from the removed blade must be treated as representative of similar blades left in-service. The requirement is that creep tests must be performed on the material removed, but there usually is not enough material to perform full size uniaxial creep tests, let alone a comprehensive set of tests required for robust evaluation of bulk creep properties.

The development of the small ring creep test [29] allows for multiple tests on small quantities of blade material. Minimum creep strain rate data was obtained from the root of a third stage heavy duty gas turbine blade (Fig. 11a) at $800^{\circ} \mathrm{C}$. Stress and minimum creep strain rate data were converted to equivalent uniaxial test data through the mechanics based reference stress method in conjunction with the equivalent gauge length of the material (sect 2.2). Data were found to fit well with the uniaxial data for Inconel 738 virgin as cast material (as it is what the blade root represents) as in Fig. 11b [27].

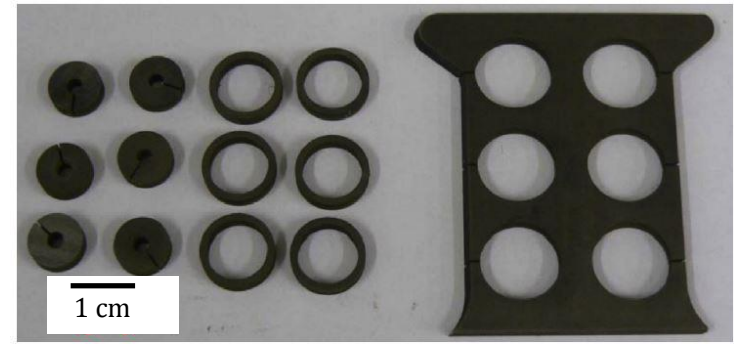

(a)

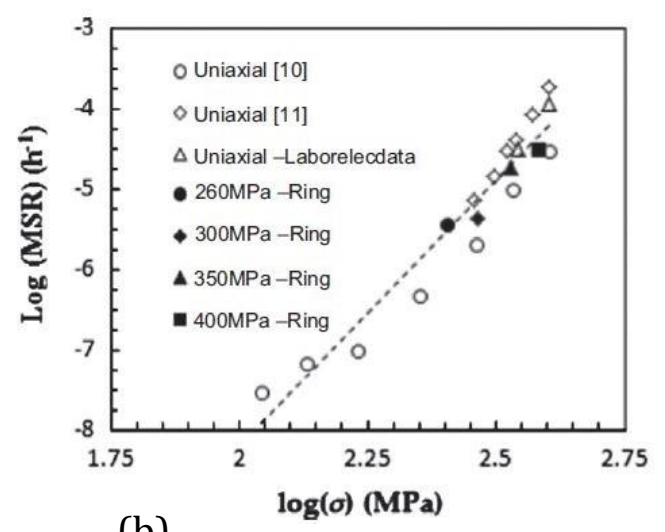

(b)

Figure 11: Blade root, with specimens removed by spark erosion and (b) Log-log plot of stress as a function of minimum strain rate, for a small ring and uniaxial tests at $800^{\circ} \mathrm{C}$ [27]

Quality strain data is achievable with the small ring test. Further data interpretation procedures are necessary to obtain remnant life assessment. Available strain based methods include the Monkman-Grant relationship and Omega method. Further work is required in this area.

Small punch testing on a single crystal superalloy, 'CMSX-4' [76], at $950^{\circ} \mathrm{C}$ and $1050^{\circ} \mathrm{C}$ in the [001] crystallographic orientation were done [59]. A good linear fit was found for 
the punch load and time to rupture. $K_{s p}$ values of 0.6 at $950^{\circ} \mathrm{C}$ and 0.8 at $1050^{\circ} \mathrm{C}$ were found. Discrepancies were attributed to directional coarsening of $\gamma^{\prime}$ particles (rafting), this occurs more rapidly at higher temperatures in single crystal materials [72]. A Wilshire fit (eq.13) was applied to small punch stress vs time to rupture data and good agreement was found with uniaxial data (Fig.12) [15].

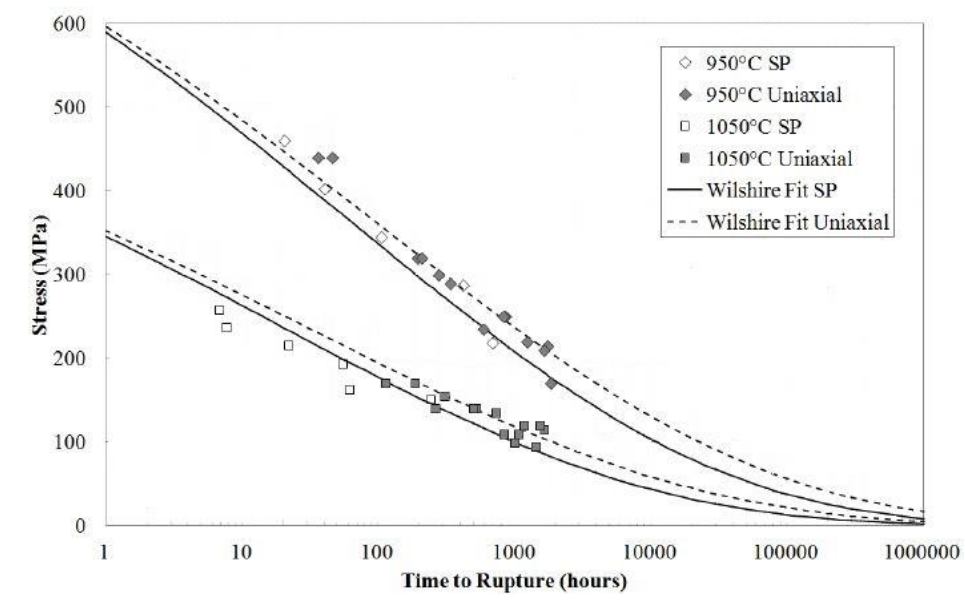

Figure 12: Wilshire plot for time to rupture as a function of stress for CMSX-4. SP represents small punch, alongside uniaxial data [59].

\section{The Need for Standardisation of Impression Creep Testing}

\subsection{Background}

The impression creep test has been used successfully in the creep strength ranking of in-service components for $0.5 \mathrm{CrMoV}$ and $\mathrm{P} 91$ steels as shown in earlier sections of this paper, which has many benefits as it allows for the targeting of vulnerable components and allows for the focus of resources on those components. For $0.5 \mathrm{CrMoV}$ pipework there is a comprehensive database available for comparison of tested materials. The impression creep test is also able to produce a large volume of useful data from small amounts of material which include the ability through stepped-load and steppedtemperature tests to multiple sets of minimum creep strain rate data from a $10 \times 10 \times 2.5 \mathrm{~mm}$ test specimen, useful in alloy development [2].

\subsection{Work Needed}

For wider implementation in power plant life management it is necessary to standardise the basic definitions of test rigs, specimen dimensions, sampling and specimen preparation, temperature and loading control and displacement measurement etc. A recommendation for most of these issues has been discussed by Hyde et al. [10]. This would help in the production of bespoke purpose built impression creep rigs that adhere to precise load and temperature control requirements to produce 
consistent data across laboratories economically. A detailed description of the test can be found in the guidelines for small scale testing [77].

\section{Concluding Remarks}

Evidence for the utility of small specimen creep tests has been reviewed and cases for creep strain rate data and rupture life data of a comparable standard to uniaxial test data is present.

Limited testing and practice with the sub-size uniaxial specimen means that some key issues that occur during the application of a load to the specimen remain unresolved. This and the acute sensitivity to the atmospheric composition of the test furnace make the test procedure difficult.

The impression creep test has been used extensively in industry and so a large database exists for strength ranking of established ferritic power plant pipeline steels. A framework for the general application of the strength ranking method is needed for it to be generally applied, along with development in standardisation of the test method.

In its current form the small punch creep test can only be useful as a qualitative measure of creep strength. This is based on the absence of mechanics based conversion of strain and rupture data and the limited understanding of the deformation curve produced by the test. This is indicated by the reluctance of industry to incorporate the test into life assessment procedures. However, due to relatively short test times in comparison with impression creep, small punch creep testing has the potential to be a more efficient strength ranking tool.

Accurate strain rate data, the capability to test a broad range of materials and larger load line displacements than the impression creep test make the small ring creep test a strong candidate for creep strain rate measurement. The test is in its infancy, so the development of a database for a broad range of materials is in order. Furthermore, the development of strain based lifing methods for the exploitation of the small ring test data would be beneficial for the future uptake of the test method.

Two bar rupture data shows promise when compared with uniaxial data. The immediate concern is to carry out more testing, in order to illustrate the repeatability of the test.

Small specimen creep tests should not be looked at in isolation, but should be looked at as a suite of tests that can be used in combination to test the components mentioned in this review. 


\section{References}

1. DECC: 'Digest of UK Energy Statistics (DUKES)': 2014.

2. Naveena, V. Vijayanand, V. Ganesan, K. Laha, and M. Mathew: 'Application of Impression Creep Technique for Development of Creep Resistant Austenitic Stainless Steel', Procedia Engineering, 2013, 55, 585 - 590: doi: http://dx.doi.org/10.1016/j.proeng.2013.03.299: 6th International Conference on Creep, Fatigue and Creep-Fatigue Interaction

3. M. Mathew, J. G. Kumar, V. Ganesan, and K. Laha: 'Small Punch Creep Studies for Optimization of Nitrogen Content in 316LN SS for Enhanced Creep Resistance', Metallurgical and Materials Transactions A:, 2013, 45a, 731-737.

4. T. H. Hyde, C. J. Hyde, and W. Sun: 'A Basis for Selecting the Most Appropriate Small Specimen Creep Test Type', Journal of Pressure Vessel Technology, 2014, 136, 024502.

5. T. Hyde, and W. Sun: 'Some Considerations on Specimens Types for Small Sample Creep Tests.', Materials at High Temperatures, 2010, 27(3), 157-165.

6. T. Hyde, C. Hyde, and W. Sun: 'Theoretical Basis and Practical Aspects of Small Specimen Creep Testing.', Journal of Strain Analysis, 2012, 48(2), 112-125.

7. A. Garzillo, G. C., L. Moscotti, and R. L.: 'A Technique for the Residual Rife Assessment of High Temperature Components Based on Creep-Rupture Testing Welded Miniature Specimens', International Journal of Pressure Vessels and Piping, 1996, 66, $223-232$.

8. M. Askins, and K. Marchant: 'Estimating the Remanent Life of Boiler Pressure Parts': Tech. Rep., EPRI, 1987.

9. Y. Kadoya, T. Goto, S. Date, T. Yamauchi, T. Saida, and T. Sada: 'Assesment of remaining life of fossil power plant parts by means of a miniature creep rupture test', ISIJ International, 1990, 30(10), 854-861.

10. T. H. Hyde, W. Sun, and S. J. Brett: 'Some Recommendations on the Standardization of Impression Creep Testing', In: Creep \& Fracture in High Temperature Components Design \& Life Assessment. 2, ECCC, 2009:.

11. S. Brett: 'Small Scale Sampling and Impression Creep Testing Applied to Aged CrMoV Steam Pipework Systems.', In: EPRI International Conference on Advances in Condition and Remaining Life Assessment for Fossil Power Plants Coal, Gas and HRSG. Hilton Head Island, South Carolina, 2012:.

12. S. J. Brett, B. Kuhn, J. H. Rantala, and C. J. Hyde: 'Impression Creep Testing for Material Characterization in Development and Application', In: Materials for Advanced Power Engineering. 10th, Liege, Belgium, 2014.

13. T. H. Hyde, K. A. Yehia, and A. A. Becker: 'Interpretation of Impression Creep Data Using a Reference Stress Approach', International Journal of Mechanical Sciences, 1993, 35, 451-462.

14. T. Hyde, and W. Sun: 'Multi-step Load Impression Creep Tests for a 1/2Cr1/2Mo1/4V Steel at 565C.', Strain, 2001, 37, 99-103.

15. W. Sun, T. Hyde, and S. Brett: 'Small Specimen Creep Testing and Application for Power Plant Component Remaining Life Assessment', In: Integrity, Reliability and Failure of Mechanical Systems. IRF, 2013:.

16. B. Gulcimen, and P. Hahner: 'Determination of Creep Properties of a P91Weldment by Small Punch Testing and a New Evaluation Approach', Materials Science \& Engineering, A:, 2013, 588, 125-131.

17. J. P. Rouse, F. Cortellino, W. Sun, T. H. Hyde, and J. Shingledecker: 'Small Punch Creep Testing: Review on Modelling and Data Interpretation', Materials Science and Technology, 2013, 29(11), 1328-1345.

18. P. Dymcek, and F. Dobe: 'Small Punch Testing of Exposed High-Pressure Steam Pipelines', In: Pressure Vessels and Piping. Paris, France: ASME, 2013:

19. C. W. Agreement: 'Small Punch Test Method for Metallic Materials', CEN, 2006, Brussels, Belgium.

20. J. Chakrabarty: 'A Theory of Stretch Forming over Hemispherical Punch Heads', International journal of mechanical sciences, $1969,12,315-325$

21. T. Hyde, and W. Sun: 'Interpretation of Small Punch Creep Test Data for Ductile Materials', Metallurgical Journal, 2010, 63, 25-33.

22. F. Cortellino, J. Rouse, W. Sun, and T. Hyde: 'A Study on the e eect of initial plasticity on the small punch creep test for a P91 Steel at $600 \mathrm{oC}$ ', In: SSTT - Determination of mechanical properties of materials by small punch and other miniature testing techniques. Graz, Austria, 2014:.

23. Z. Yang, and Z. wen Wang: 'Relationship Between Strain and Central Deflection in Small Punch Creep Specimens', International Journal of Pressure Vessels and Piping, 2003, 80, 370-404.

24. K. Kobayashi, I. Kajihara, H. Koyama, and G. Stratford: 'Deformation and Fracture Modes during Small Punch Creep Tests', Journal of Solid Mechanics and Materials Engineering, 2010, 4, 75-86. 
25. D. Blagoeva, and R. Hurst: 'Application of the CEN (European Committee for Standardization) Small Punch Creep Testing Code of Practice to a Representative Repair Welded P91 Pipe', Materials Science \& Engineering: A, 2009, 510-511, 219-223.

26. W. Sun, and T. H. Hyde: 'Determination fo Secondary Creep Properties Using a Small Ring Creep Test Technique', Metallurgical Journal, 2010, 53, 185-193.

27. C. Hyde, T.H.Hyde, W.Sun, S.Nardone, and E. D. Bruycker: 'Small ring Testing of a Creep Resistant Material', Materials Science \& Engineering A, 2013, 586, 358-366.

28. T. H. Hyde, and W. Sun: 'A Novel, High-Sensitivity, Small Specimen Creep Test', Journal of Strain, 2009, 44, 171-185.

29. T. H. Hyde, B. S. M. Ali, and W. Sun: 'Analysis and Design of a Small, Two-Bar Creep Test Specimen', Journal of Engineering Materials and Technology, 2013, 135, 041006.

30. B. S. M. Ali: 'Development of Non-Destructive Small Specimen Creep Testing Techniques': Ph.D. thesis, University of Nottingham, 2013: Chapter 5.

31. T. H. Hyde, K. A. Yehia, and A. A. Becker: 'Interpretation of Impression Creep Data Using a Reference Stress Approach', International Journal of Mechanical Sciences, 1993, 35(6), 451-462.

32. T. Hyde, M. Stoyanov, W. Sun, and C. Hyde: 'On the Interpretation of Results from Small Punch Creep Tests', Journal of Stain Analysis, 2009, 45, 141-164.

33. A. C. Mackenzie: 'On the Use of a Sing Uniaxial Test to Estimate Deformation Rates in Some Structures Undergoing Creep', International Journal of Mechanical Sciences, 1967, 10, 441-458.

34. R. Sim: 'Reference Stress Concepts in the Analysis of Structures During Creep', International Journal of Mechanical Sciences, 1970 12,561 .

35. R. Sim: 'Evaluation of Reference Parameters for Structures Subjected to Creep', Journal of Mechanical Engineering Science, 1971, $13,47$.

36. A. Tonti: '8 - Residual life evaluation techniques, defect assessment procedures and monitoring in coal power plants': In: A. Shibli, ed. Coal Power Plant Materials and Life Assessment. Woodhead Publishing: ISBN 978-0-85709-431-5, 2014:199 - 228: doi:http://dx.doi.org/10.1533/9780857097323.2.199.

37. B. Dogan, and T. Hyde: 'Industrial Application of Small Punch Testing for In- Service Component Condition Assesment: An Overview', In: Pressure Vessels and Piping. Toronto, Ontario, Canada: ASME, 2012:

38. S. Brett: 'The Application of Small Scale Sampling and Impression Creep Testing to Power Plant', In: ECCC Conference: Creep \& Fracture. Rome, Italy, 2014:.

39. J. Janovec, D. Polachova, and M. Junek: 'Lifetime Assessment of a Steam Pipeline', Acta Polytechnica, 2012, 52, 74-79.

40. J. D. Parker, and J. Purmenski: 'Assesment of Performance by Monitoring In-service Changes in Materials Properties', In: 9 th Euro. Conf. on Fracture, Reliability and Structural Integrity of Advanced Materials. Varna, 1992:1051-1056.

41. A. Dedov, I. Klevtsov, T. Lausama, and D. Neshumayev: 'Method of Small Samples for Assessment of Properties of Power Plant Components: Sampling Devices and Stress Concentration in Dimples', In: J. Veivo, and P. Auerkari, eds. Life Management and Maintenance for Power Plants, vol. 2. Helsinki, Finland, 2007:180-192.

42. Rolls-Royce: 'Scoop sampling extraction of material samples for examination and analysis': 2010: Last accessed: $13 / 06 / 2015$.

43. T. Hyde, and W. Sun: 'Application of Impression Creep Test Data for the Assessment of Service Exposed Power Plant Components', Metallurgical Journal, 2010, 58, 138-145.

44. B. Dogan: 'Sampling and Small Punch Testing in the Power Generation Industry', In: Determination of the Mechanical Properties of Materials by Small Punch Testing and Other Miniature Testing Techniques. Ostrava, CZ, 2010:

45. J. P. Rouse, W. Sun, and T. Hyde: 'The E«ects of Scoop Sampling on the Creep Behaviour of Power Plant Straight Pipes', Journal of Strain Analysis, 2013, 48(8), 494-511.

46. S. Brett, J. Rantala, and S. Holmstrom: 'Practical Application of Impression Creep Data to Power Plant', In: Baltica IX: Life Management and Maintenance for Power Plants. Helsinki-Stockholm-Helsinki, Finland, 2013:

47. W. Sun, T. H. Hyde, and S. J. Brett: 'Application of Impression Creep Data in Life Assessment of Power Plant Materials at High Temperatures', Journal of Materials Design and Applications, 2008, 222, 175-182.

48. T. H. Hyde, W. Sun, and C. J. Hyde: Applied Creep Mechanics: McGraw Hill, 2014.

49. Y. Li, and R. Sturm: 'Determination of Creep Properties from Small Punch Creep Test', In: ASME Pressure Vessels and Piping Division Conference. Chicago, illinois, 2008: 
50. D. Blagoeva, Y. Li, and R. Hurst: 'Qualification of P91 Welds Through Small Punch Creep Testing', Journal of Nuclear Materials, 2011, 409, 124-130.

51. T. Hyde, and B. Ali: 'On the Determination of Material Creep Constants Using Miniature Creep Test Specimens', Journal of Materials Engineering Technology, 2014, 136, 021006.

52. 'Metallic materials Uniaxial creep testing in tension Method of test BS EN ISO 204:2009': 2009.

53. D. Blagoeva, N. Taylor, and R. Hurst: 'State-of-the-Art Report on Application of Miniaturized Testing Techniques to Support Life Management Decisions for Nuclear Plants': Tech. Rep., JRC, 2007.

54. J. Shan, Z. Qian, and X. Ling: 'Influence of Oxidation to Small Punch Creep Test', Key Engineering Materials, 2007, 353-358, 461464.

55. J.Parker: 'Life Management of Creep Strength Enhanced Ferritic Steels in Boiler and Piping', Energy Materials, 2007, 2(2), 95103.

56. F. Larson, and J. Miller: 'A Time-temperature Relationship for Rupture and Creep Stresses', Trans. ASME, 1952, 74, 765-775.

57. T. Izaki, T. Kobayashi, J. Kusumoto, and A. Kanaya: 'A Creep Life Assessment Method for Boiler Pipes using Small Punch Creep Test', International Journal of Pressure Vessels and Piping, 2009, 86, 637-642.

58. Z. Abdallah, V. Gray, M. Whittaker, and K. Perkins: 'A Critical Analysis of the Conventionally Employed Creep Lifing Methods', Materials, 2014, 7, 3371-3398.

59. S. Jeffs, R. Lancaster, and T. Garcia: 'Creep Lifing Methodologies Applied to a Single Crystal Superalloy by use of Small Scale Test Techniques', Materials Science and Engineering: A, 2015, 636, 529-535.

60. B. Wilshire, and P. Scharning: 'Creep ductilities of 9 - 12\% chromium steels', Scripta Materialia, 2007, 56(12), 1023 - 1026: doi: http://dx.doi.org/10.1016/j.scriptamat.2007.03.003.

61. M. Prager: 'The Omega MethodAn Engineering Approach to Life Assessment', Journal of Pressure Vessel Technology, 2000, 122, 273-280.

62. S. J. Brett: 'Unpublished',

63. B. Dogan: 'Small Punch Testing and Application in Power Generation Industry', In: Pressure Vessels \& Piping. Baltimore, Maryland, USA, 2011:

64. S. J. Brett: 'Case Study: Early type IV cracking on two retrofit grade 91 steel headers': Tech. Rep., RWE npower, 2008.

65. S. Brett: 'The Practical Application of Small Scale Sampling and Impression Creep Testing to Grade 91 Components', In: 7th International Conference on Advances in Materials Technology for Fossil Power Plants. Hawaii, USA: EPRI, 2013:.

66. F. Dobes, and K. Milikcka: 'Application of Creep Small Punch Testing in Assessment of Creep Lifetime', Materials Science and Engineering A, 2009, 1, 510-511.

67. F. Hou, H. Xu, Y. Wang, and L. Zhang: 'Determination of Creep Property of 1.25Cr0.5Mo Pearlitic Steels by Small Punch Test', Engineering Failure Analysis, 2013, 28, 215-221.

68. B. Kim: 'Small Punch Creep Behavior and Nondestructive Evaluation of Long Term Aged AISI 316L Stainless Steel', Internatinal Journal of Precision Engineering and Manufacturing, 2013, 14(7), 1267-1270.

69. H. Nobakhti, and N. Soltani: 'Evaluating Small Punch Test as Accelerated Creep Test Using LarsonMiller Parameter', Experimental Techniques, 2014, , 1-6.

70. J. G. Kumar, K. Laha, and M. Mathew: 'Small Punch Creep Testing Technique for Remnant Life Assesment', Applied Mechanics and Materials, 2014, 392-394, 739-743.

71. K. Harris, and J. Wahl: 'Improved Single Crystal Superalloys, CMSX-4 (SLS) [La+Y] and CMSX-486', Superalloys, 2004, 1, 45-52.

72. R. C. Reed: 'The Superalloys: Fundamentals and Applications' Cambridge University Press. 2006

73. A. Shibli, and K. Coleman: 'Failures of P91 steel at the West Burton plant in England raise concerns about the long term behavior of the advanced steel': Tech. Rep., ETD, EPRI, 2003.

74. F. Abe: ' 1 - Grade 91 heat-resistant martensitic steel': In: A. Shibli, ed. Coal Power Plant Materials and Life Assessment. Woodhead Publishing: ISBN 978-0- 85709-431-5, 2014:3 - 51: doi:http://dx.doi.org/10.1533/9780857097323.1.3.

75. L. Cipolla, and J. Gabrel: 'New Creep Rupture Assessment of Grade 91', In: Industry and Research Experience in the Use of P/T91 in HRSGs/Boilers. London, UK, 2005:.

76. T. Pollock: 'Nickel-Based Superalloys for Advanced Turbine Engines: Chemistry, Microstructure and Properties', Journal of Propulsion and Power, 2006, 22(2): 361-374. 
77. ECCC: 'Data Acceptability Criteria and Data Generation: Recommendations for Creep Testing of Post Exposed (Ex-Service) Materials': 2014.

78. J. P. Rouse, W. Sun, T.H. Hyde and A. Morris: 'Comparative assessment of several creep damage models for use in life prediction', International Journal of Pressure Vessels and Piping. 2013, 81-87.

79. BSI: 'BS EN 10216-2:2013 Seamless steel tubes for pressure purposes - Technical delivery conditions. Part 2: Non-alloy and alloy steel tubes with specified elevated temperature properties' . BSI Standards Limited 2013. 